\title{
Una investigación sobre modelos culturales en el medio rural ahonda en las relaciones entre arte, territorio y población
}

La investigación tuvo lugar durante el pasado año 2021 a cargo de un equipo multidisciplinar integrado en El Cubo Verde, una red informal que aglutina iniciativas de arte vinculadas a entornos rurales. En estos meses de trabajo se han identificado las diferencias y similitudes entre los diferentes modelos de gestión cultural en el medio rural con la finalidad de conocer cómo arte y cultura sirven de motor de cambio. Una vez terminada la investigación, exponemos aquí las principales ideas que concluyen sus coordinadores.

David García Ferreiro | El Cubo Verde

URL de la contribución <http://www.iaph.es/revistaph/index.php/revistaph/article/view/5047>

Culturarios-Humus de iniciativas culturales en el campo es un proyecto surgido gracias al apoyo de la Fundación Daniel y Nina Carasso, que ha buscado conocer los diálogos entre arte, territorio y habitantes, como pieza clave de las políticas, programas y proyectos culturales que se desarrollan en el medio rural. Para ello, trata de aportar nuevos modelos de gestión y creación de la cultura en el campo, facilitando medios para el acceso y la producción a la cultura, desde el conocimiento colectivo, facilitando las relaciones entre población, agentes culturales e instituciones.

Esta iniciativa parte de un equipo perteneciente a la red de El Cubo Verde: un espacio de autoaprendizaje, que nace como soporte para una comunidad interpelada por el interés hacia los espacios de arte en el campo. Culturarios. Humus de iniciativas culturales en el campo, está diseñado y apoyado por Coco Moya, artista y música; coordinado por el cineasta y gestor cultural David G. Ferreiro (Imago Bubo); la artista Virginia López (Proyectos Artísticos Casa Antonino) como coordinadora editorial; la cineasta y fotógrafa Hadriana Casla como coordinadora del documental; y el artista y educador Alejandro Piccione como coordinador de la investigación de campo.

Culturarios consta de dos elementos claves, Geografías Culturales, un espacio de investigación formado por un amplio equipo de personas (Irene Sanfiel, Fidel Darias, Lorena Lozano, María Montesino, Lucía Camón, los

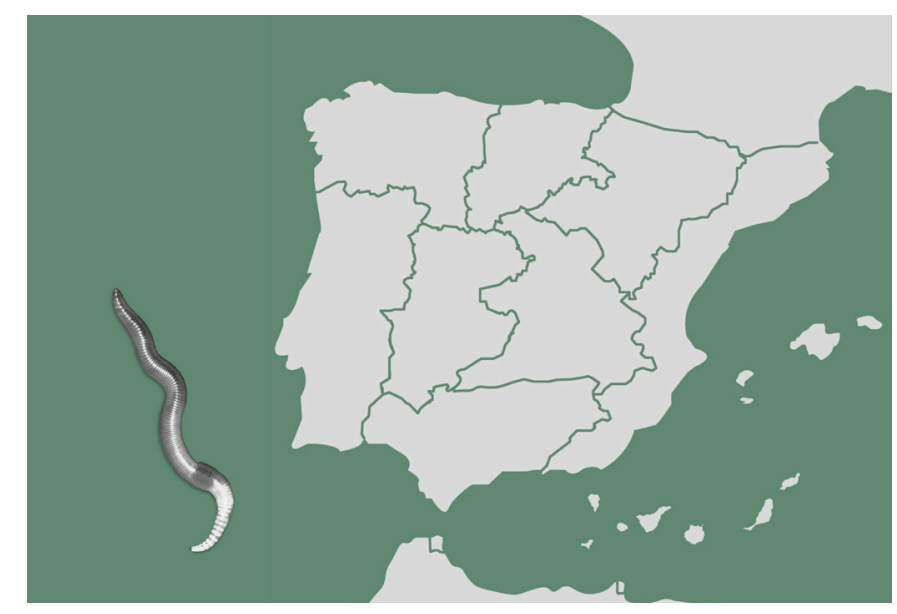

División territorial para la investigación realizada | diseño Hadriana Casla

integrantes de Campo Adentro, Pol Parrhesia, Jorge Gallardo y Sabah Walid), que han buscado recoger el mayor número de sentires e identidades culturales que albergan los proyectos insertos en las regiones rurales del territorio estatal; y Red Difusa, un espacio audiovisual de reflexión colectiva y de carácter más intimista que ha buscado conocer la mirada de las personas que habitan los territorios rurales.

Este proyecto es también un reflejo de un mayor interés por lo que sucede en el campo y desde el campo. En este proceso nos hemos visto abocados a apreciar los rurales bajo una lente caleidoscópica, pues nos encontramos entre los rurales de recursos carboníferos de cuencas asturleonesas y los rurales del turismo del 


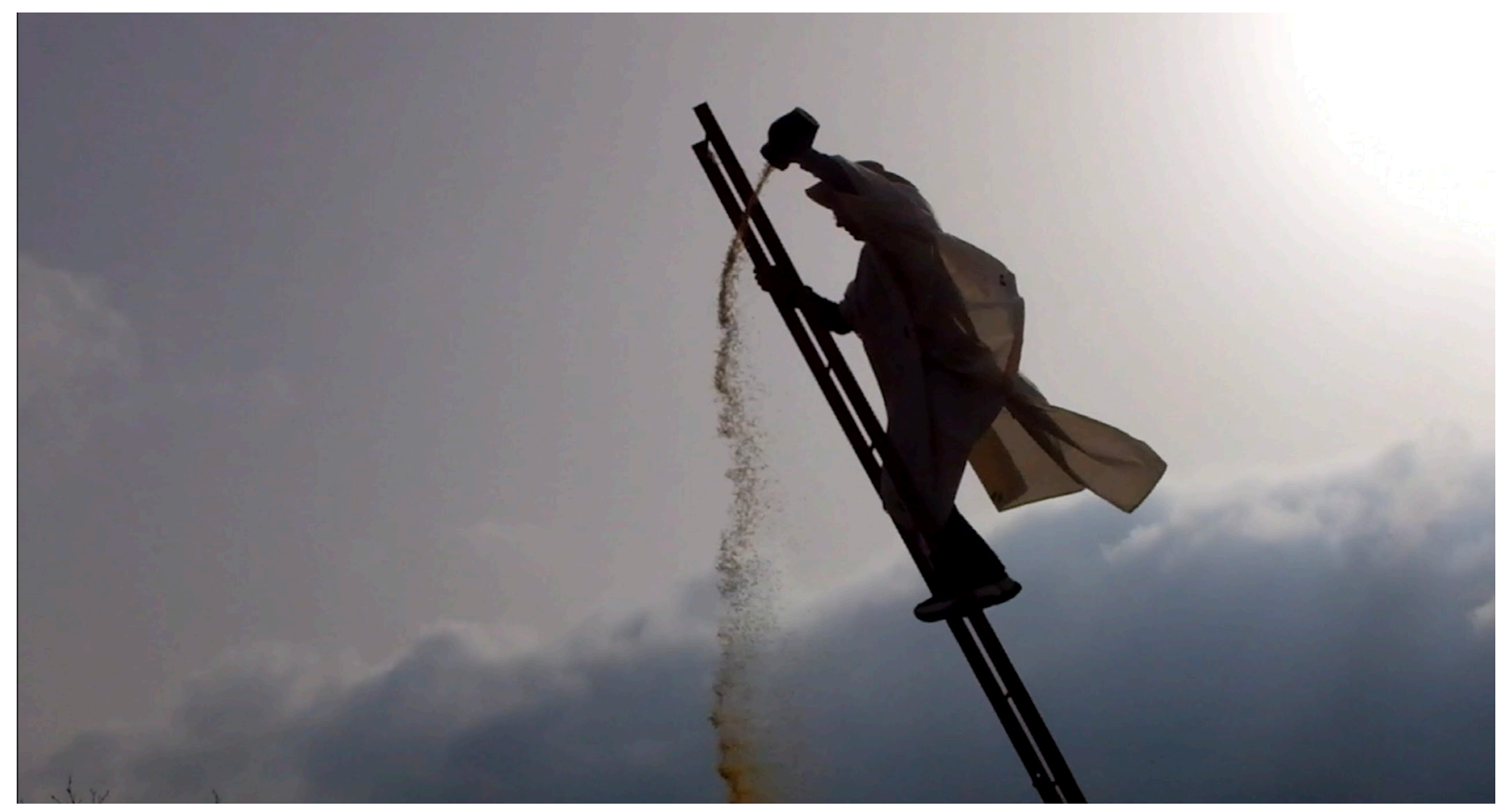

Fotograma del documental Red Difusa | Dorien Jongsma

archipiélago canario, entre los rurales de minifundios y hacenderas de zonas montañesas frente a los rurales del latifundio y caciquismo del sur, entre las costas rurales del norte y las costas masificadas y explotadas del este peninsular, cuna de las segundas residencias.

Estos rurales aún no han sido tenidos en cuenta desde las políticas institucionales, ya que continúan siendo bastante genéricas e inespecíficas dentro de un contexto de progresiva globalización de los mercados agroalimentarios del que no es ajeno el estado español. Como dicen las compañeras de BeeTime "La verdadera labor de mediación cultural en los campos del sur la ha estado realizando y la realiza la agroindustria: su labor de destrucción de conocimientos precipita a sus pobladores a una reconstrucción sobre vacío".

Esa labor de fagocitación de los procesos tradicionales por parte de la agricultura y ganadería industrial, que se erige como un vaciador demográfico, junto al desprecio de las tradiciones y saberes de nuestros ancestros, son los elementos que llevan a la extinción de las culturas identitarias de los habitantes del campo y a la ruptura de sus lazos vecinales. El franquismo atacó a las raíces, nos desarraigó de la tierra; el neocaciquismo sigue trabajando en ello, en que olvidemos que la tierra es de todos, que nuestros cantos, nuestras danzas y nuestro sentimiento con la tierra que pisamos son verdaderos. $\mathrm{Si}$ a esto le sumamos la falta de una educación que sensibilice en cuanto a los valores comunitarios del territorio, tenemos una bomba a punto para seguir alimentando la diáspora de las habitantes de los rurales.

En este sentido y dentro del marco que atañe a la investigación, la figura de la mediación cultural en la mayoría de los casos se hace indispensable. Pues rescata, o al menos busca hacerlo, tradiciones y prácticas artesanales del olvido, favorece la comunicación intergeneracional y el intercambio de conocimientos, promueve la participación y la colaboración vecinal frente a un monopolio cultural, una cultura del espectáculo pasivo, que ni siquiera supone una retroalimentación para la ciudadanía, fuera de las grandes urbes. Todo esto viene a abrir nuevas líneas de acción y pensamiento dentro 
del contexto social desde el inicio del siglo XXI. No nos queda otra que tomar consciencia de ello y volver a las calles, a sentarnos al fresco en las noches de verano, volver a juntarnos al calor de la lumbre, y seguir creciendo en comunidades pequeñas, que es la verdadera vereda a seguir. Tenemos que convertir la resiliencia en resistencia

Puede que sea muy pretencioso que nosotras, las que también erramos, propongamos soluciones a tantas realidades diferentes, pero este camino nos ha permitido percibir algunas cosas que creemos que necesitan mencionarse, aunque simplemente sirvan para abrir un debate, una charla a través de la que seguir creciendo. Por lo que aquí va nuestra lista (con posibles erratas):

$>$ Es necesario generar más diálogo, es necesaria la escucha. Se debe asumir el diálogo con esas personas lejanas a nuestros idearios o prácticas con el fin de ampliar el nivel de entendimiento de ambas partes y abrir la posibilidad a puntos en común, ya que si no orientamos nuestras prácticas desde el conflicto, estas no tienen sentido.

> Si desde la educación no se trabaja en poner en valor las prácticas colaborativas y las diversidades identitarias de nuestros pueblos, difícilmente podrá haber una conti-

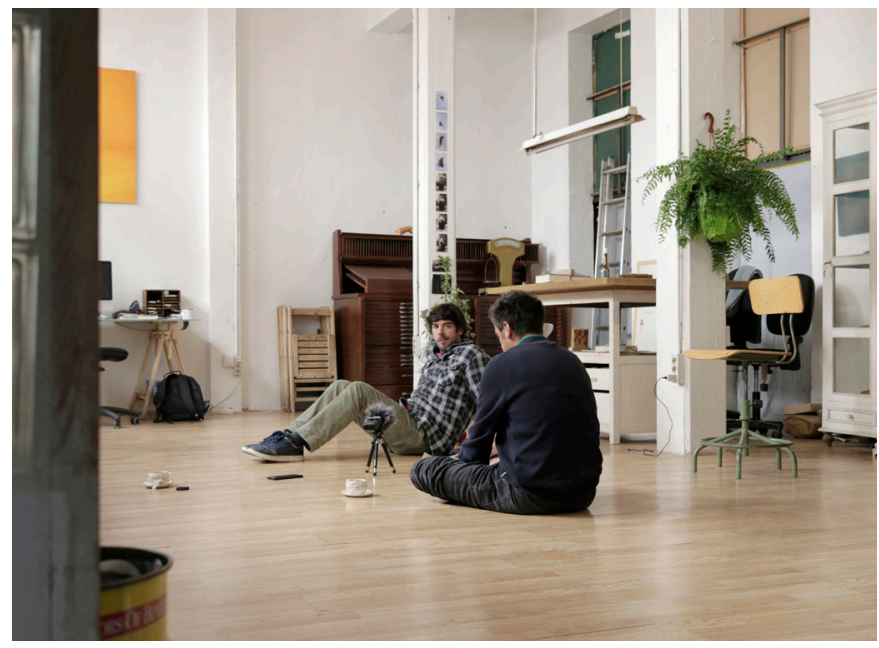

Fotografía tomada durante una de las entrevistas dentro de la investigación del proyecto Culturarios | fuente BeeTime nuidad o un entendimiento claro por parte de una comunidad a la que se le ha ido sustrayendo su propia cultura.

$>$ Es necesario hacer partícipes y empoderar a las audiencias a través de la escucha de sus necesidades. Solo de esta manera las iniciativas fluirán en concordancia con el apoyo y el protagonismo de la vecindad.

$>$ Respecto a la sostenibilidad demográfica y biodiversidad, ateniéndonos a la Ley 42/2007, de 13 de diciembre, del Patrimonio Natural y de la Biodiversidad por la cual se establece la obligación de elaborar inventarios de conocimientos tradicionales que permitan su divulgación práctica y conservación y de la cual deriva el Inventario de Conocimientos Tradicionales relativos a la Biodiversidad, creemos necesario extender la idea de que las mediadoras culturales no solo podemos divulgar una gran parte de esos conocimientos, sino que debemos comprometernos en cierta medida con ese fin.

$>$ Estamos en un camino de originar modelos entre la tradición ancestral y lo contemporáneo. Nuevos modelos que abracen la diversidad y eviten la homogeneización.

> Se precisa arrojar una herramienta de carácter divulgativo en cuanto a prácticas que se consideren de interés, que exponga el valor cualitativo de estos proyectos artísticos y culturales que engloba el rural estatal.

Como conclusión final, hemos tomado consciencia de que hemos de huir de la mirada romántica de lo rural, también que debemos dejar de hablar de lo rural para hablar de los rurales, comenzar a pensarlos como espacios de resistencia, de creación para la supervivencia de las especies, como espacios radicales. Esto nos lleva a dejar de hablar de lo bucólico; pero no nos puede (ni nos debe) impedir hablar de la idea del amor; amor hacia el proyecto, hacia el territorio, hacia las gentes que lo habitan, hacia la vecindad. Mientras tanto, seguimos caminando por un incierto presente hacia un más incierto futuro; tenemos que seguir creciendo, y no nos queda otra opción que seguir creciendo en red. 